International Journal of Computer Integrated Manufacturing, Volume 22, Issue 12, 2009,

Pages 1073-1088

\title{
A knowledge management framework to support product-service systems design
}

\author{
David Baxter; Rajkumar Roy; Athanasia Doultsinou; James Gao; Mohamad Kalta
}

\begin{abstract}
This paper presents a framework for knowledge reuse in a Product-Service Systems design scenario. The project aim is to develop a methodology to capture, represent and reuse knowledge to support product development in a collaborative enterprise context. The three core elements are: design knowledge, manufacturing capability knowledge, and service knowledge. There are three principal components of the proposed methodology. The first is a process based design model: defining design according to specific tasks, and associating previous knowledge with those tasks. The second is manufacturing capability knowledge: supporting feature based design and manufacture through representing machining features, best practices in machining and inspection, and machining capability. The third component is service knowledge: ensuring that design takes account of the service requirement. The developing paradigm of Product-Service Systems and the requirement for co-design of products and services has influenced the structure of the knowledge base, as well as outlining specific service related requirements. This paper presents the proposed knowledge base structure along with a detailed case study in which the proposal was developed and validated.
\end{abstract}

Keywords: design; innovation management; product development; design for service; design for manufacture; knowledge management

\section{Introduction}

This paper aims to address some of the challenges from the developing Product-Service Systems (PSS) paradigm in a manufacturing context. Manufacturing companies are generating an increasing proportion of their revenue through service. This recognition of the increasing importance of service led to the development of the servitization paradigm, in which products and services are offered to customers as an integrated package: servitization is considered as a position where product and service are inseparable (Morelli 2002). PSS, as a special case of servitization (Baines et al., 2008) focuses on the combination of products and services to deliver customer value.

Companies who design and manufacture products are uniquely able to apply their in-depth engineering knowledge to the variety of customer applications. This in-depth product knowledge also gives them a significant advantage in offering maintenance and repair services. The compelling business case for offering services as an addition to products is strongly linked to the significantly higher profit margins available in downstream, or customer facing, operations (Wise, 1999).

There are few studies on the impact of a PSS business strategy on the product-and-service design strategy. It is recognised in literature that it is not sufficient to simply design products and add service: system level design is necessary (Aurich et al., 2006).

A key challenge in the development of technical products is managing product data. Because managing product data is such a challenge, particularly in a life cycle context, the design process and resulting business 
model of engineering companies is often centred on the 'master product model' concept. Since we have identified that products and services are required to be designed in concert, and that organisations are increasingly focused on the delivery of service, this business model must be scrutinised in light of the developing PSS paradigm. PSS design includes not only integrated product-and-service design but also business process design: the company who developed the PSS must also develop and implement the systems to deliver it.

Integrated Technical Product-Service System (t-PSS) design will rely on a structured approach to the development of the product and service. This includes the requirement to adapt the master product model concept in light of the PSS design challenge. This requirement is considered here in terms of knowledge reuse: how can company knowledge, in particular product models, manufacturing methods, and service methods, be represented in such a way that supports the change in focus required as a result of the emerging PSS design challenge?

This paper describes the development of an integrated knowledge management framework to support PSS design. The framework is demonstrated using examples from a detailed case study.

\section{Literature review}

This section describes the theoretical underpinning of this research from the following categories: design knowledge reuse, manufacturing capability, and PSS design.

\subsection{Design knowledge reuse}

In order to briefly describe the context of this project, some references to knowledge management literature will be made. The paradigm of 'knowledge reuse' makes various assumptions, including a technocratic view of knowledge management (Earl 2001) with codification as the primary focus (Hansen et al., 1999). It is further assumed that the development of mature products can effectively rely upon explicit knowledge communicated through information systems (Hansen et al., 1999).

In previous work, we developed a method to reuse engineering design knowledge (Baxter et al., 2007). Three knowledge types were supported: process knowledge, product knowledge, and task knowledge. The design process made reference to the product model at the activity level. The process based design knowledge reuse method provides project guidance and monitoring, a framework to organise information and knowledge retrieval, and a central repository of product data. This framework will be adapted and extended to take account of design, manufacturing and service knowledge in a PSS design context.

\subsection{Manufacturing capability research}

Manufacturing capability research can be considered in two categories: strategy level and operations level. Strategy level manufacturing capability research is concerned with issues such as production capacity and organisational strategy. Operations level manufacturing capability research addresses capability at the machine level, and often refers to Statistical Process Control (SPC - see, for example, Yu et al., 2005; Motorcu \& Güllü 2006; Gijo 2005). The manufacturing case study in this research is aimed at operations level capability, and in particular, machining capability. In machining capability research, feedback to design is not well addressed. Manufacturing process planning research is largely focused on the development of automated solutions (e.g. Yongtao \& Jingying 2006; Aziz \& Chassapis 2005). Whilst automation saves time in execution, the detailed knowledge capture exercise associated with knowledge based systems is an expensive process, applicable only in large companies (Yoo \& Kim 2002). 
Manufacturing process planning is also relevant, as a key consideration in product development. For a description of computer aided process planning, see (Culler \& Burd 2007). There is some conflict in applying process planning systems at the conceptual stage of design, due to the high level of detail required for CAPP and the lack of standard frameworks for manual process planning to support the reuse of manufacturing methods. Our research indicates that industry practice in machining process planning still relies on manual processes. As such, we are advocating a lightweight knowledge management method that provides knowledge of best practices with minimal implementation and maintenance effort.

\subsection{Service knowledge research}

Service is a core element of PSS design. There are few formal approaches to service knowledge capture and reuse available in the literature, indicating that it is a developing area. Current developments in service and maintenance literature are tending towards intelligent monitoring: prognostics and health management, which combines monitoring (Masri et al, 2004; Yao \& Warren, 2005) with computational methods (Dunsdon et al, 2008) and algorithmic analysis in an integrated framework (Lee et al, 2006) to optimise maintenance intervention. This predictive maintenance and intelligent service management does not take account of normative practices (Scandura et al. 2004) such as crew checklists in aircraft. It also does not include design feedback mechanisms.

\subsection{PSS Design Research}

The developing PSS research field shows that within an integrated product-service system, the product, service and business model need to be developed in an integrated fashion.

Baines et al (2008) discuss the state of the art in PSS, stating that a PSS is "an integrated product and service offering that delivers value in use". They suggest that a successful PSS needs to be designed from a client perspective, at the system level. They also suggest that organisational structures of PSS providers must change in order to support PSS delivery. They conclude that there is currently limited guidance for PSS design and delivery. Tukker and Tischner (2006) also propose that new business models are a key element of PSS, and that careful design of the PSS is required. Evans et al. (2007) found that the producer must play a key role in Product-Service System design, whilst also working closely with other supply chain members. This is due to the producer having intimate knowledge of design and of high volume manufacturing. They investigated 10 companies in the food industry. Morelli (2002) suggests that PSS design must develop methods to take account of shifts in cultural norms, and that improved methods to represent services are required.

The life cycle oriented technical service design method (Aurich et al., 2004) was later modified to incorporate PSS concepts (Aurich et al., 2006). This method proposes an integrated, systematic approach to product and service design. They suggest an integrated process model that applies processes from a library. Their methods do not indicate how to reuse PSS knowledge and information. Tukker and Mont also emphasise the need to focus on the system perspective in PSS design (Mont \& Tukker 2006).

The key message of PSS design research to date is that a PSS design methodology is required to support two key elements: conceptualisation of the PSS itself and of the supporting business model. Existing design methodologies and tools are recognised to have a potential contribution to PSS design, however they must be modified or extended to properly reflect the PSS design problem. It is not the intention of this research to develop a PSS design methodology, rather to develop a framework that supports knowledge reuse in a t-PSS design scenario. The framework must therefore support product, service and business model design. 


\subsection{Knowledge structure for PSS modelling}

Knowledge modelling enables the efficient interchange of data relating throughout the system life cycle. Various models have been proposed, such as the manufacturing knowledge model developed by GuerraZubiaga and Young (2008). Robust, web-based technical solutions to data exchange include ontology models. Ye et al. (2008) demonstrate an ontology for integrating supply chain management activities. As this research progressed and uncovered the emerging requirements of PSS, it was identified that they would have a significant impact on the structure of the knowledge reuse framework. The challenge of PSS design includes the co-development of products, services and business models. As such, a product centric structure (e.g. Young et al., 2007, Guerra-Zubiaga and Young, 2008) is no longer appropriate. There are some exceptions to this: in very large scale products such as ships, a significant part of the life cycle management challenge is configuration management. In this large-single-product environment, a central product model is an appropriate structure for PSS management. In smaller scale products such as vacuum pumps, several hundred pumps may be installed at a single customer site. The range of products in place and the range of applications each product is applied to results in a need to focus at the broader 'system' level in order to effectively manage the PSS life cycle.

Three classes are commonly applied as an upper level structure for both product- and software- development modelling purposes: Product, Process and Resource (PPR). Maropoulos et al (2002) apply the PPR classes to a manufacturing planning problem: integrating design and manufacturing. Chandra and Kamrani (2003) apply the PPR classes to a knowledge management framework to support product design in an extended enterprise scenario. Both methods extend the PPR class structure in order to support detailed descriptions of additional domains such as design, manufacturing, and maintenance. Huang and Mak (1999) describe the need to integrate PPR in a design (concurrent engineering) activity. In each case, the application of PPR classes enables a range of activities and items to be described in order to support product design. The methods do not appear to support service- or organisation- design.

The original application of the three PPR classes appears to come from computer science. Fenton (1991) made reference to them in his 1991 book on software metrics. The widespread adoption of CAD systems, plus the introduction of product data management (PDM) systems contribute towards the need to formalise product descriptions. Concurrent engineering, and in particular computer applications to support it, brings about the need to describe the downstream activities (processes and resources) that constitute the domain of interest. Software models of design processes and artefacts require a structured description of the constituent elements in a way that is easily transferred to a software system. The direct application of a software modelling approach makes sense from the perspective that: since it will be described using a software system, the description method can directly apply software modelling methods.

\section{Case companies}

During this research project, three companies have been engaged at varying levels. Each company will be described in terms of their products and markets, their approach to design, and their maturity with respect to PSS.

Company 1 are a manufacturer of vacuum pumps for a variety of industrial applications. Their principal market is the semiconductor industry, within which many critical processes operate in a vacuum and require process gas removal. The nature of the semiconductor industry brings two conflicting requirements: ultra high reliability due to the high expectation of the technologically advanced industry and the high value of semiconductors, coupled with the ability to cope with aggressive chemicals and materials involved in semiconductor manufacturing and equipment cleaning processes. Design is very much technically driven: engineering knowledge is highly regarded in this company. Historically, the key focus in the design process 
has been the engineering phase. Recently, the new product introduction (NPI) process is taking account of an increasing amount of downstream requirements from the conceptual design stage, engaging engineers and CAD designers directly with manufacturing and service personnel. Service accounts for approximately $50 \%$ of total revenue. Product sales have historically been separate from service sales, and this remains the case for small customers. The current strategy with larger customers is to offer integrated pump management solutions, in which products are sold alongside a service and maintenance package. Integrated pump management systems are operated via network connections to each pump within a customer site. Pricing structures and product design strategies remain 'product plus service' however the integrated nature of the current sales strategy and the availability of advanced product management reflects a significant move towards PSS.

Company 2 are providers of machine tools. Currently they offer lathes, grinding machines and vertical and horizontal machining centres. The company has grown through acquisition. A selection of their machine tools are manufactured in-house, however several of their product lines are manufactured by external companies. They currently operate in the low to medium price range, typically selling to small-to-medium enterprises (SMEs). The nature of flexible machining centres means that they serve a variety of manufacturing applications. Product design for the outsourced machines takes place at the supplier. The company provides requirements specification and participates in design review activities. Product sales are generally separate from service sales, however the company do offer technical support for new customers from process optimisation to a full 'turnkey package' including the machine, fixture, and NC code for a given component. They do not offer remote product monitoring. Their separate service and product sales strategy positions them as a traditional manufacturing company rather than a PSS provider.

Company 3 are a large aerospace manufacturer. They design and manufacture aero engines for military and civil applications. Their sales strategy in the civil sector is increasingly focused on a leasing model in which airlines pay a fixed price for every hour the engine is operating. This is having a significant impact on the mechanical aspects of product design through the approach to life cycle cost analysis. It has also influenced the systems element: advanced engine health management is now a key activity within the company. Sensor systems indicate engine health. They must be integrated with the business systems, including supply chain management to ensure optimal maintenance expenditure. With respect to PSS, company 3 are considered as a leading figure. The scale and complexity of their products and the current organisation of the business means that the gradual shift from a product focused business to a service focused business is having a major impact.

\section{Research Methodology}

A case study approach was adopted in this research. According to Gerring and McDermott (2007), the case study approach represents an analysis in which one or a few units are studied in detail in order to provide insight to a broader class of units. In this research, the units are all manufacturing organisations developing mature, complex electro-mechanical products. The intention is to study these organisations in order to develop an understanding of current practice, and to use them as test cases for the knowledge framework proposal to support PSS design.

\section{Knowledge capture}

Knowledge capture was divided into three separate stages: design, manufacturing and service. Design knowledge capture involved a combination of interviews and secondary data describing the design process. In total, 5 interviews took place with senior designers, and a process model was developed to describe the 'as-is' design process. The process model was developed iteratively, and validated by the designers. 
Manufacturing knowledge capture took place using multiple methods. Approximately 30 interviews and 4 workshops were held in total. 3 days were spent observing the machining activity. Company documents describing materials, tooling, machining processes, design processes and quality systems were also used in understanding the existing company knowledge and in developing the framework. Four initial interviews were carried out using the critical incident technique (Gremler, 2004). The primary question in this stage was "From your experience, describe the most recent situation in which you either observed or experienced something that impressed you as an outstanding example of \{positive, or effective; negative, or ineffective\} behaviour". The responses were subjected to a thematic analysis, which is "...a process for encoding qualitative information. The encoding requires an explicit "code"... A theme is a pattern found in the information..." (Boyatzis, 1998). In this example, notes taken during the interviews were analysed to identify key terms. This analysis contributed to the development of an initial manufacturing knowledge framework. The remaining interviews and workshops supported the development of the knowledge base content, structure and usage scenarios. Detailed descriptions of manufacturing processes (machining and inspection) were captured.

Service knowledge capture took place in two stages. The first stage included the development of an outline service knowledge framework. For this stage, 10 semi-structured interviews took place with NPI personnel to identify examples of service knowledge applied in design. A semi-structured interview approach was adopted. Notes were taken during the interviews, and the notes were subjected to thematic analysis. The themes were applied to a service knowledge framework proposal, which was validated with the participants. The second stage focused on the development of detailed service process examples. 10 interviews were held to identify knowledge applied in the field service activity. These interviews supported the creation of service process descriptions.

Validation took place in each case with the users. The integrated system was validated in a workshop format.

\subsection{Representing design (process) knowledge}

One important element of design knowledge capture, particularly in the design of mature products, is process modelling. A prescriptive design process model shows the best practice sequence of tasks which contribute towards the creation of the final product. Figure 2 shows the design process model developed as a result of the case study. The process notation refers to activities (square corners) and data sets (round corners). This division of task and data is applied according to the Design Roadmap method (Park \& Cutkosky 1999). This enables the inclusion not only of task relevant knowledge, but also of any required input data. This modelling approach was applied to previous work on design knowledge reuse (Baxter et al., 2007).

The best practice design process was captured for a vacuum pump, an example of which is shown in Figure 1. The process is divided into two main stages: conceptual and detailed design. The main focus of this work is conceptual design, however detailed design is also shown to indicate the resulting process flow. The conceptual design activity begins with the creation of a project team. In parallel, the requirements specification, product family definition, module structure definition and service package design activities are carried out. Service package design is currently carried out during the detailed design activity, however the recognition of an integrated product and services sales strategy brought about the requirement to design the service package concept at this early stage. This combination of tasks feeds into the engineering requirements data set.

Figure 1: roots-claw vacuum pump

The design process in Figure 2 represents a 'to-be' process. Various activities additional to current practice are proposed to better support PSS design. One such activity is manufacturability analysis, which could be formally applied at the early stages, providing an input to the performance modelling activity. Dry pumps rely 
on very small clearances between rotors and stators in order to produce the highest possible vacuum. Machining tolerances are therefore critical in providing high performing and reliable pumps. The engineering requirement includes a specification of pumping capacity, vacuum capability and expected power consumption, which implies a machining tolerance requirement. Therefore, this model proposes a manufacturing analysis activity to take place within the conceptual design stage in order to verify the commercial validity of the project. Roughly speaking, smaller clearances result in conceptually superior products. When operating very close to the manufacturing capability threshold, smaller clearances also result in higher production costs through more costly manufacturing methods (e.g. boring vs. interpolating) and higher scrap rates.

Figure 2: design process model

Two service focused activities have also been added to the design process: service package design and service location decision. Conceptual level service package design takes place alongside the system requirements specification. A detailed level service package design process is required as an addition to this model.

Alongside manufacturing process design, service process design needs to take place. Since the knowledge capture activity did not extend to service process design, it is not included in this version of the process. Service knowledge capture is described in the next section.

\section{7. $\quad$ Representing manufacturing (machining and inspection) knowledge}

The manufacturing knowledge capture activity took part in two phases: the first phase set out to identify a manufacturing knowledge structure and to develop a prototype knowledge base. The second phase set out to capture detailed examples and usage scenarios and to record them in the knowledge base. The detailed manufacturing knowledge structure was developed to support three key activities: machining planning, inspection planning, and product design.

Geometric features are applied to support the integration of manufacturing and design. STEP AP224 is used to describe machining features, including: boss; turned knurl; thread; marking; rib top; round hole; outside profile; pocket; removal volume; revolved profile; outer round; flat face; protrusion; rounded end; slot; spherical cap; step; compound feature; replicate feature. STEP AP224 is also used to describe tolerances. Geometric tolerances include: angularity; circular runout; concentricity; cylindricity; flatness; parallelism; perpendicularity; position; roundness; straightness; surface profile; symmetry; and total runout. Dimensional tolerances include size and location.

Machining and inspection planning processes are developed according to a component description. In design terms, the focus is often broader: if not product level then certainly module level. Feature level knowledge is also very relevant in detailed design. Identifying relationships between these various levels is critical in developing a support system that can be applied to multiple user groups.

For manufacturing engineers, a key support function is providing access to best practice machining methods. Initially, existing machining processes were captured and stored in the system in order to identify the required content. Geometric features were classified according to how they were applied in design through a series of interviews and workshops. An investigation then took place to identify best practices according to these features. The proposed method applies scaleable machining features with a range of sizes rather than a fixed size. It also applies scaleable machining process descriptions, using surface speed and chip thickness in place of spindle rpm and feed rate. An example of a best practice machining feature, a dowel hole, is shown in Figure 3.

Figure 3: example best practice feature - dowel hole 
The tolerances associated with this best practice feature are presented according to two different processes: boring and reaming. The machining activities describe the reamed hole, however the tolerances also show a bored hole. The user is able to easily compare how the bored hole differs (better position tolerance; worse inside diameter tolerance).

Manufacturing processes at the component level are the second important interface for knowledge support in manufacturing planning. The process shows the sequence of activities. Each activity shows the resource used: in a machining process this refers to the tool. Activity descriptions also include tooling data including chip thickness, surface speed, and spindle load. The ability to describe machining processes at the component level independently from the feature level is necessary since component level (and multi-component fixture level) optimisation may indicate sub-optimal tooling for a given feature in order to optimise overall tool count.

\subsection{Service knowledge part 1: service in design}

Following a thematic analysis of notes taken during 10 semi-structured interviews, the service knowledge structure shown in Figure 4 was proposed. The main categories are: tooling, spares, serviceability, maintenance, and training. Knowledge from each of these categories is required in the NPI process.

Figure 4: proposed service knowledge structure

The tooling category refers to tooling required to service the pumps in the field and at the service centre. New or special tooling required for a new product needs to be developed within the NPI project. Decisions taken regarding assembly and test methods must consider the service facilities. The volumes associated with original manufacture will always be higher than those at the service facility, since products made at a single manufacturing location will be serviced at many service locations around the world due to the distributed nature of the service business. As such, optimal manufacturing methods (e.g. flow lines, dedicated automation) may not be optimal for the lower volume service facility. Design decisions at this stage should seek to optimise whole life cost. Test systems have caused issues in the past, where automated test methods have been applied to production. The design of the test method had not taken into account the lower volume of products being tested at the service centres. As a result, the decision to apply manual methods at the service centres required the development of the test equipment and the test procedure.

Spares are a designation for components available to the after-market as replacement parts. Spares definitions may dictate that certain parts replacements are carried out in groups. For example, a single seal may only be available as part of a kit. That kit may include several washers, seals 'o'-rings or gaskets, according to the expected requirement for a full or partial rebuild. Other rebuild parts kits may also be available, containing various wear parts according to the recommendation for parts which should be replaced as part of every product rebuild.

Serviceability is indicated through feedback from service personnel to designers. Feedback may include actual time taken in the service process, problems encountered, ideas for improvement, and design change requests. Whilst design change requests have a formal feedback mechanism, there is not currently a method for providing feedback of the other non-critical elements.

Maintenance in this context refers to the maintenance processes and procedures. One such example, a test process, is shown in Protégé is a free, open source ontology editor developed by the Stanford Center for Biomedical Informatics Research. It is used as a knowledge-base framework for knowledge solutions in various communities, including biomedicine, intelligence gathering, and corporate modelling (http://protege.stanford.edu).

Figure 5. Test procedures developed within the NPI process need to be developed according to the most economically favourable test equipment. The calculation may differ according to regional differences for a 
given volume: lower labour cost may result in a higher preference for manual processes, whereas high labour cost may lead to a preference for automated processes.

Training refers to the requirements for procedures and documentation as well as project planning to support product launch. Documentation describing service and maintenance procedures is a key part of the training requirement. Hands-on training also takes place: a service technician trained by the NPI team may travel to the various service centres to train key personnel, or service technicians from the various global sites may travel to a central location to receive hands-on training.

\subsection{Service knowledge part 2: service operations}

Various service activities take place at customer sites: installation, maintenance, commissioning, exchange, product management and repair. Dedicated service centres carry out product maintenance and repair.

The context of the second stage of service knowledge capture was 'service knowledge applied in service operations'. The knowledge capture activity took place through a series of interviews with service centre personnel. The outcome of these interviews was twofold: first, the knowledge structure described in Figure 4 was examined and extended to take account of their knowledge requirements. Second, a process modelling activity took place to represent a selection of processes carried out in the service environment. An example process (a product test process in a service centre), described using the Protégé knowledge base editor tool, is shown in Protégé is a free, open source ontology editor developed by the Stanford Center for Biomedical Informatics Research. It is used as a knowledge-base framework for knowledge solutions in various communities, including biomedicine, intelligence gathering, and corporate modelling (http://protege.stanford.edu).

Figure 5. Protégé is a free, open source ontology editor developed by the Stanford Center for Biomedical Informatics Research. It is used as a knowledge-base framework for knowledge solutions in various communities, including biomedicine, intelligence gathering, and corporate modelling (http://protege.stanford.edu).

Figure 5: Partial service (test) process represented in the Protégé system

\section{Framework development}

In developing the PSS knowledge framework, the results of the design, manufacturing and service knowledge capture activities were combined with the findings from the literature study. The review of the literature showed that PSS design requires an integrated approach; this was a central consideration in the development of the integrated framework.

The first activity was to develop a strategy and upper level structure suitable for modelling PSS. Following that, a detailed level ontology could be developed to represent the content and relationships of the specific domain knowledge. This will be described using examples developed in the case study. Figure 7 shows the upper level PSS structure that enables the description of a combined product- and business- system (Baxter et al., 2008).

Figure 6: life cycle system structure

The upper level class 'life cycle system' indicates the combination of business model, product, and service. The reference to 'life cycle' (rather than simply PSS) indicates the 'through life management' challenge. A life cycle system can be described at any level of abstraction, from the overall PSS (e.g. an availability contract at a customer site with 200 pumps installed) to a subset of that system: a product in use, a maintenance team, or a service facility, for example. The life cycle system view also enables any given stage in a product life cycle to be described: conception, design, use, maintenance, disposal, and so on. At the 
detailed level, the configuration of the system structure will differ according to the specific needs of a given industry, supply chain, or organisation.

\section{Ontology development}

Using life cycle system as a central class, the structure shown in Figure 7 was proposed for modelling a PSS in order to provide product- and service- design support. This has been developed with reference to a technical PSS, in which detailed descriptions of design, manufacturing and service are required. The technical system used in the development and validation of this model is a system of vacuum pumps installed at a customer site operated according to an operations contract which indicates an overall level of availability (i.e. 99.97\%). There are various pump, customer and process types to consider. Decisions on replacement stock levels and installation of slave systems with automatic switching are made by the vacuum service provider.

Figure 7: integrated knowledge framework structure

The central class 'life cycle system' is principally comprised of three classes: product, process and resource. The system also comprises various descriptive classes: requirements, behaviour, logistics, operating methods, and installation environment. The requirements at the system level are comprised of service features (Doultsinou et al., 2008), which are defined as 'attributes of service that deliver value to the customer'. Examples of service features include uptime, response, and capability to quickly address problems.

The product class is comprised of architecture and requirements. This distinction supports the division of product development into conceptual and detailed phases. The conceptual phase identifies requirements, and the detailed phase develops modules, components and a bill of materials. At the detailed level for machined components, STEP AP224 classes can be used to define the machining features.

The process class is comprised of activities and resources. This is developed in line with the Process Specification Language (PSL - see Gruninger \& Menzel 2003) core, which defines processes in terms of activities, objects and timepoints. Time is a requirement for process execution, however is has not been included as part of the proposed framework.

The resource class, in a similar manner to the PSL 'object' class, refers to any resource that is used by a process. Resource subclasses include facilities (e.g. manufacturing; service), equipment (e.g. tools; office equipment), person, material and information resource. The information resource class contains drawings, standards, detailed machining features, tolerance data, materials data, and others.

There are a great deal of relationships between classes: many classes reference other classes. Those relationships are not shown in the simplified system level knowledge structure diagram. The requirement for the knowledge structure and the class relationships arises from the usage scenarios. Some examples of usage scenarios are given in the validation section.

\section{Implementation}

The ontology was implemented using the Protégé knowledge base editor tool. The Protégé tool allows the creation of classes, properties and relationships; and the implementation of a knowledge base through the creation of instances of those classes.

Knowledge implemented in the system includes: requirements, design features, manufacturing features, machining processes, machining best practices, inspection processes, manufacturing resources (tools, machines), product descriptions, module descriptions, and component descriptions. Examples of the implemented knowledge will be provided through the description of manufacturing and service knowledge usage scenarios. 


\section{Scenario development and validation}

The structure and relationships of the knowledge base were developed and refined according to the content and usage scenarios captured during the case studies. Developing an ontology and defining classes and instances is an iterative and content dependent activity (Noy and McGuinness 2002).

The usage scenarios support the development and validation of the knowledge base structure and content. The aim of the integrated knowledge structure is design support. Our research activity developing the manufacturing and service knowledge structures identified that the knowledge contributors require motivation to spend time populating the system. Both manufacturing and service managers aim to keep data recording to a minimum. Therefore two important aspects contribute to this motivation: minimal time required for inputting data, and maximum potential for the system to support the activities of the knowledge provider. An integrated approach to developing the knowledge flow is therefore favoured over a unidirectional service / manufacturing $\rightarrow$ design knowledge flow. Various scenarios were proposed in order to identify the knowledge flows required to support manufacturing, service, and design. These are described in the following sections.

\subsection{Service knowledge scenarios}

The scenario used to develop and validate the service knowledge structure is taken from a service facing perspective. If the framework can support service operations, then the population and maintenance of the content will be taken on within service, and the feedback to design will maintain a higher level of relevance and accuracy.

Four scenarios were considered during the development of the ontology: service feedback to design; ramping up the service activity after the product has been in the field for 12 months; on-site product monitoring within an availability contract; and implementing a new product into the service operation. The final scenario will be described here.

An outline process model describing the service implementation scenario is shown in Figure 8 . The first activity relates to defining the product. Inputs from the knowledge framework include the product architecture class (BOM, modules) and inputs from the resource class (e.g. drawing). The product description is likely, in practice, to represent a family of products with multiple variants. A further critical element is the intended customer application, defined using the 'installation environment' class. This includes references to resources including equipment and personnel.

Figure 8: knowledge requirements of the service implementation scenario The product size and application type dictate the requirements for floor space and chemical treatment facilities. A template service (disassembly and rebuild) process forms part of the product release documentation. In Figure 8 this is supported by the two classes 'activities' and 'resources'. This process will have been evaluated by service personnel at the prototype stage. In combination with the projected volume, this input is applied to the development of the service process. Activities and resources (personnel, information, tooling) required by the process are compared against the existing facility. Tooling, training, and test procedures are developed according to the existing facility, in line with the volume of products expected. The expected volume of products is a critical design feature for service process design. A low volume of products, say between 1 and 5 per week, may be carried out using generalist tooling in a flexible workshop, carried out by personnel with a varied and wide ranging expertise. A medium volume of products, say between 10 and 50 per week, may warrant some specialist service bays and a division of the various activities (e.g. receive, disassemble, clean, inspect, rebuild, test). A higher volume of products may warrant further division of these activities and the application of flow line design principles. The description of this scenario 
identifies that the knowledge requirements for the service implementation activity are supported by the knowledge structure. At a detailed level, our implementation does not currently describe customer applications (installation environment), BOM, or product modules in detail. Activities and resources for service process development can be described in detail, as shown in Protégé is a free, open source ontology editor developed by the Stanford Center for Biomedical Informatics Research. It is used as a knowledge-base framework for knowledge solutions in various communities, including biomedicine, intelligence gathering, and corporate modelling (http://protege.stanford.edu).

Figure 5.

\subsection{Manufacturing knowledge scenarios}

Two scenarios were developed and validated: designer accessing manufacturing capability (tolerance) data, and manufacturing process planning support. Regarding machining process planning, manufacturing engineers identified that the capability of the system to provide feature-based best practice machining process knowledge would save them time in the NPI process and reduce the time taken to implement the process into manufacturing. A cost saving of $£ 100 \mathrm{~K}$ was calculated per major design iteration, through reduced time required on the machine to optimise the machining process. An example best practice feature is shown in Figure 3. A more detailed description of the process planning support is given in Baxter et al. (2008).

Regarding designers accessing machining capability data, the machining knowledge base was presented. Designers reported that the system provides too much irrelevant information, that they had to 'drill down' through too many levels to access to the data relevant to them, and that this would prevent them from accessing the system: "if we have to dig for it, it won't be used". The designers described their requirements, which do not include details of the manufacturing process. As a result, the template shown in Figure 9 was developed to provide designers with access to manufacturing capability data relating to component types in a familiar and visual format. The decision was taken to create a template according to two different manufacturing capability levels, described according to scrap rate. One template would describe a component with a $\mathrm{C}_{\mathrm{pk}}$ of 1.66 , which represents a very low $(\sim 0 \%)$ scrap rate. The second template has tighter tolerances on all critical features, representing a $2 \%$ scrap rate. The tolerances corresponding to this scrap rate were assigned to the various features according to historical production data. This method of presenting tolerances to the designers performs two functions. First, they are presented in a manner which is easily accessed and used by the designers. Second, the scrap rate can be used as a simple cost multiplication factor: a known component cost increases by a minimum of $102 \%$ with a $2 \%$ scrap rate. Good manufacturing practice would (somewhat arbitrarily) suggest a set of tolerances according to a $\mathrm{C}_{\mathrm{pk}}$ of 2 , or six sigma. In a high performance product whose manufacturing tolerances directly impact the performance, this must take account of the overall commercial picture: the value impact of the performance improvement vs. the cost impact of the machining tolerance. A performance analysis activity showed that the impact of the two tolerance levels on the pump clearances and expected performance (including throughput and ultimate pressure) was significant.

Figure 9: design template with best practice tolerance data

The designer scenario shows that whilst the manufacturing knowledge framework does include the knowledge required to support this scenario, it does not support it well in its current form (i.e. via the Protégé interface). As such, an implementation of this system should take into account the requirement to present the knowledge in a usable and familiar format according to the particular user. 


\subsection{Conceptual design: service knowledge feedback scenario}

The primary purpose of the proposed knowledge framework is to provide designers with access to service and manufacturing knowledge. Within the case study company, feedback to designers from the product use phase currently exists in two key streams. The first, least frequent mechanism is the design change request. If a service engineer identifies a problem they can create a request for a design change. The second mechanism is via the ERP system, which records details of all transactions throughout the supply chain. NPI project managers request custom reports to provide feedback on issues such as service frequency and product life. They may also identify component life, through parts replaced. They can also access service reports.

Standardised reporting of the resource usage developed specifically for design feedback would be a valuable input to NPI. Examples of useful existing data include labour hours and parts replaced, as major drivers of service cost. If actual service costs are understood, then more accurate life cycle cost calculations can be made for new PSS offerings: product management contracts which include service and spare parts provision. 'Hours run' against parts replaced would also indicate the expected life of components or modules in a given application. There is a wide variation in expected life since certain applications and cleaning chemicals aggressively degrade the pumps. This is both a cost factor and an essential feedback mechanism describing reliability.

Regarding reliability, designers suggested in the interviews that indication of failure cause is necessary for a full appraisal of a product failure. 'Failure cause' is not a simple issue. There is some risk associated with service technicians assigning root cause to product failures, since the cause is not always clear from the symptoms. For every product service carried out, symptoms are recorded but root cause is not investigated. For every warranty claim, an investigation is carried out to identify root cause in order to assign the cost of repair. Where unusual or repeat failures occur, detailed investigations are carried out at the customer site by applications specialists to identify and rectify the root cause and improve system performance. Data from all three types of investigation, including the reports produced and the photos taken of the pump during disassembly, should be available to the design team in case they want to investigate any given product failure in more detail. Our study recognises that there is both cost (due to the time required for the investigation) and risk (due to the possibility of assigning the wrong cause) associated with requesting 'root cause' from a service report.

Regarding feedback to design, in summary, we have proposed that design feedback take place through standard reports to collate and display data collected by the ERP system. The detailed description of the report content, and a case example, is identified as further work.

\section{Activity level knowledge provision: context filters}

One of the objectives of the research project was to develop context specific knowledge management filters. This recognises that with an increasing amount of content available in a knowledge management system, there is a requirement to ensure that people are able to access knowledge relevant to their work function. The approach taken to ensure that appropriate knowledge can be delivered is to provide an activity level mechanism, which links knowledge resources with activities. The precise mechanism within the Protégé implementation is the inclusion of a 'knowledge resource' slot in the activity class. This slot enables any instance from any class in the knowledge base to be associated with an activity. Whilst the protégé system limits the content of the knowledge resources to alphanumeric inputs, the class structure supports the extension of the principle to include hypermedia links, attached files, and links to other systems. Examples of these knowledge filters at the activity level are provided to illustrate design support with manufacturing and service knowledge. 


\subsection{Activity level knowledge provision: requirements specification}

The requirements specification activity is one of the first activities to take place in the design project, as shown in the design reference model in Figure 2. The purpose of the activity is to identify and document the requirements in order to develop an engineering specification for the product or system. Concurrent activities include product family definition (defining variants in the product range, i.e. 100, 200 and $600 \mathrm{~m}^{3} \mathrm{~h}^{-1}$ models), module definition (defining the strategy for common modules across the range), and service package design (the outline strategy for service delivery).

In the knowledge base, the requirements specification activity includes various knowledge resources, including requirements specifications from previous products. One such example is the requirements knowledge resource. This resource references a number of requirements instances from previous products such as 'service prime cost target', 'availability requirement', 'environmental conditions requirement', 'equipment interface requirement' and many others. These requirements reference the product they refer to (e.g. product-x-interface-requirement).

This requirements definition object shows all of the requirements categories applied within that project. Each requirement instance then provides access to the detailed content applied to each category. For example, the 'availability' category indicates the requirement for the product start-up latency $(<2 s)$. The content of the maintainability requirement includes: '5 year service interval', 'stable design', 'traceability', 'clear wiring instructions', and others. The manufacturability requirement shows the facilities available at the enterprise, factory, cell, and station level. This enables the design team to assess manufacturing location and equipment in terms of performance and cost requirements at this early concept stage. The detailed manufacturing analysis activity is a separate task, and is described next.

The detailed reference to the requirements specification from previous projects supports the design team in developing specifications for the new design project where they are not explicitly indicated by the market analysis activity by giving them a clearly defined starting position. Various personnel are involved at this stage, including engineering, manufacturing, marketing, sales, and customer application specialists. Each group should be able to offer their understanding of the changing importance of these previously applied categories. The knowledge resource object provides a method to make them available at the right stage of the product development process such that they can have maximum impact.

The next stage in the development of this requirements knowledge resource is to associate requirements with in-service measurements and feedback to identify how well the requirements were met in practice. This extension represents further work.

\subsection{Activity level knowledge provision: manufacturability analysis}

Following the creation of the engineering requirements specification, the two subsequent design process activities are manufacturability analysis and performance modelling. Support for the manufacturability analysis task will be described here. The purpose of the task is to support the optimal definition of product parameters to meet the conflicting demands for pump performance and prime cost target. With a rotary vacuum pump, there is a relationship between the internal rotor-stator clearances and the throughput and vacuum pressure achievable at a given motor speed. A clearance is calculated according to the various manufacturing tolerances which contribute, and their expected distribution. This indicates the range of assembly conditions and the likely failure rate. Input values to this calculation include the tolerances contributing to the clearance. Alongside each tolerance, the likely scrap rates for a given manufacturing method will support the manufacturing cost calculation.

Knowledge resources associated with the manufacturability analysis activity provide the tolerance and scrap rate data. Two types of manufacturing knowledge object are included: best practice components (to indicate 
the best practice process, tools, machine, tolerances applied and measured scrap rates), and guaranteed tolerance values specified according to a generic manufacturing method, with expected scrap rates.

For similar components, the best practice component types are a good starting point, since they indicate the process type and tolerances achieved according to each critical feature (critical features contribute to the performance analysis calculation). For new or novel feature types, the more general 'guaranteed values' are used (i.e. achievable straightness on a machined feature) according to the overall dimensions of the new feature.

Having identified the particular features and manufacturing methods, the resources are applied to the tolerance analysis calculations. Various combinations of manufacturing methods can be tested in this analysis stage to balance the manufacturing cost with the required clearances. The calculated clearances are then provided as an input to the performance modelling activity. It should be noted that there is likely to be several iterations between these activities in order to satisfy the requirements of manufacturing cost and product performance.

Additional knowledge resources have also been added to the design reference model, including requirements specifications, products, components, activities, features, and tools, to provide support to the other design process activities. The knowledge resources linked to the design activities represent either best practices, or examples of good practice from previous projects.

These example applications of the knowledge resources indicate their capability to provide access to relevant knowledge according to the requirements of a particular work function or of a combined design activity.

Technically, the application of knowledge resources to activities is relatively simple, however deciding which specific resources should be applied to which specific activities should be carried out by an experienced person. A significant limitation of the approach is the high degree of manual input required. Where this approach has most value is in the definition of best practices: knowledge resources associated with a reusable process can be applied several times, offsetting the setup cost.

\section{Validation}

The integrated knowledge base was validated with three companies according to qualitative criteria. Company 1 and company 3 were involved at the early stages of this project, and helped to form the requirements of the system. Company 1 were used in the major case study. Company 2 took part in the project, but not the validation. Company 4, a company providing IT services to a range of manufacturing applications, took part in the validation activity.

Four scenarios were described, and in each case a demonstration was given to indicate the operations required to access the system and the system content. In each case, the participants were asked to rate the utility of the system on a scale of $0-5$, with 0 representing no value and 5 representing very high value. In the meetings with company 1 and 3, 3 participants gave responses for each scenario and an average is presented. Company 4 included a single participant, and the final scenario was not demonstrated due to time constraints. The four scenarios were: manufacturability analysis, manufacturing process planning support, requirements specification with service input, and service operations feedback to design. The results indicated that for each scenario, the integrated knowledge base was judged to offer moderate to high value. The results are shown in table 1.

Table 1: validation responses

\begin{tabular}{|l|l|l|l|l|}
\hline & $\begin{array}{l}\text { Manufacturing } \\
\text { analysis }\end{array}$ & $\begin{array}{l}\text { Manufacturing } \\
\text { planning }\end{array}$ & $\begin{array}{l}\text { Service } \\
\text { requirements }\end{array}$ & $\begin{array}{l}\text { Service ops } \\
\text { feedback }\end{array}$ \\
\hline Company 1 & 3.5 & 3.5 & 3.67 & 4.5 \\
\hline
\end{tabular}




\begin{tabular}{|l|l|l|l|l|}
\hline Company 3 & 3 & 2.5 & 3 & 4 \\
\hline Company 4 & 2.5 & 4 & 4.5 & - \\
\hline
\end{tabular}

\section{Discussion and further work}

A proposal has been made for a framework for knowledge reuse in a Product-Service Systems (PSS) design scenario. PSS design requires an integrated approach to the design of the product, service, and organisation. Various design tools have been developed which support engineering design, including complex mechatronic systems design.

Schemebuilder (Bradley et al. 1992) was developed at the Lancaster University engineering design centre as a software system to support the conceptual design of mechatronic products. The creation of a function structure enabled multiple schemes to be created and compared. The function model also linked to a database of components, supporting automated retrieval and design reuse. The case study did not address functional modelling as a product development approach. This represents a limitation of the proposed approach in terms of its applicability to novel product design in which functional modelling is the favoured practice. The use of requirements in place of function is not a direct exchange. Function could also be extended to additional system modelling activities such as process design.

Edalew \& Abdalla (2001) developed a computer based intelligent system for automatic tool selection. Their method provided support for materials selection, in which a user can enter details about the required material properties, which searches through a database to propose a suitable material. This section extends the Cambridge Materials Selector (Ashby and Cebon 1996). Further, Edalew \& Abdalla's system presents users with machining techniques, tools, and machining parameters, extending to cutting time and an estimate of cost for each feature. Several KBE methods were described in support of computer aided process planning, however these were rejected in this case due to the high implementation cost. Where the proposed method differs significantly from these alternative methods is primarily in the flexibility and the low implementation cost and effort. Access to material standards is required for novel designs, however for simple reuse scenarios the selection process is already made and only a small number of parameters need be applied.

This research has demonstrated support for product design with downstream inputs from manufacturing and service. Organisation design also requires further work.

The classes 'activity' and 'object' were adopted in this work from the PSL core to describe processes. Future work is required to fully implement PSL for process description, to include the classes 'timepoint' and 'activity occurrence'. This would improve the capability to describe and analyse processes in temporal terms. This is particularly applicable to the assessment of cycle time for machining processes and the time required for design or service processes.

Research is currently underway to investigate how the proposed knowledge framework can be applied within a PLM environment. The application of a PLM system will overcome some of the limitations of the prototype system relating to concurrent user access, object tracking and version control, workflow support and integration with other applications.

A dynamic approach to providing relevant knowledge applicable to a large scale enterprise system would require additional personnel profiling categories in order to dynamically assign knowledge objects to activities. This automation support for the knowledge filters approach would reduce the maintenance effort required. The effectiveness of a formal ontology based approach could be evaluated and compared with a Web 2.0 method (folksonomy / tagging) in terms of effort required and relevance of the results. 


\section{Conclusion}

Whilst there are several apparent benefits for manufacturing companies to progress to servitization or PSS business models, there is not a clear migration approach. The changing nature of the design challenge is one such area which requires considerable further research, to investigate the needs of NPI teams when faced with the challenge of developing new product-service systems.

In mature engineering industries, there is a strong case for knowledge reuse. The proliferation of knowledge based systems and design process modelling is a good indicator of this. The application of knowledge in discrete engineering scenarios is good, however knowledge management methods for PSS design and system level design support are lacking. Our research indicates that feedback from service operations to design is limited. We have also identified that a common approach to knowledge management would be beneficial for a broader application of best practices in NPI, including design processes and manufacturing methods.

An integrated knowledge framework to support PSS design has been described using examples from an industry study. The structure of the knowledge framework is based on the central class 'life cycle system'. The classes product, process and resource are used to describe the system in more detail. We have demonstrated that design knowledge can be represented using the design process. Activities which are part of that process are associated with knowledge resources. Manufacturing knowledge is represented using a STEPbased feature model to describe machining features. Manufacturing and service processes, activities and resources are represented in the framework and made available to designers and service managers. In particular, support is available for the requirements definition, service-package-design and service-processdesign phases.

\section{Acknowledgementsref_startAcknowledgementsa}

The authors would like to acknowledge the support of the Cranfield IMRC, which in turn is supported by the EPSRC. Edwards Vacuum Ltd gave a great deal of time and energy to this project. The contribution from the other members of the Decision Engineering Centre at Cranfield University is also acknowledged.

\section{References}

Aurich, J., Fuchs, C. \& DeVries, M. (2004) "An Approach to Life Cycle Oriented Technical Service Design", CIRP Annals - Manufacturing Technology, 53 (1) 151-154.

Aurich, J., Fuchs, C. \& Wagenknecht, C. (2006) "Life cycle oriented design of technical Product-Service Systems", Journal of Cleaner Production, 14 (17) 1480-1494.

Aziz, E.S. \& Chassapis, C. (2005) "A decision-making framework model for design and manufacturing of mechanical transmission system development", Engineering with Computers, 21 (2) 164-176.

Ashby, M.F., Cebon, D. (1996) Cambridge materials selector. Granta Design, Cambridge, UK.

Baines, T., Lightfoot, H., Evans, S., Neely, A., Greenough, R., Peppard, J., Roy, R., Shehab, E., Braganza, A., Tiwari, A., Alcock, J., Angus, J., Bastl, M., Cousens, A., Irving, P., Johnson, M., Kingston, J., Lockett, H. \& Martinez, V. (2008) "State-of-the-art in product-service systems", Proceedings of the Institution of Mechanical Engineers, Part B: Journal of Engineering Manufacture, 221 (10) 1543-1552.

Baxter, D., Doultsinou, N., Roy, R. \& Gao, J. (2008) "A life cycle model for product-service systems design", In: 5th International Conference on Digital Engineering Technology (DET 2008), Nantes, France

Baxter, D., Gao, J., Case, K., Harding, J., Young, R., Cochrane, S. \& Dani, S. (2007) "An Engineering Design Knowledge Reuse Methodology Using Process Modelling", Research in Engineering Design, 18 (1) 37-48. 
Baxter, D., Roy, R., Gao, J. \& Kalta, M. (2008) "Development of a knowledge capture and reuse framework for inspection and machining capability for engineering design support", IMechE part b: journal of engineering manufacture, submitted August 2008.

Boyatzis, R.E. (1998) "Transforming qualitative information: Thematic analysis and code development". Sage, Thousand Oaks, CA, USA.

Bradley, D.A., Bracewell, R.H., Chaplin, R.V. (1992) "Engineering design and mechatronics: The schemebuilder project", Research in Engineering Design 4 (4) 241-248.

Chandra, C. \& Kamrani, A. (2003) "Knowledge management for consumer-focused product design", Journal of Intelligent Manufacturing, 14 (6) 557-580.

Culler, D.E. \& Burd, W. (2007) "A framework for extending computer aided process planning to include business activities and computer aided design and manufacturing (CAD/CAM) data retrieval", Robotics and Computer-Integrated Manufacturing, 23 (3) 339-350.

Doultsinou, A., Roy, R., Baxter, D. \& Gao, J. (2008) "Developing a Service Knowledge Reuse Framework for Engineering Design", Journal of Engineering Design, submitted July 2008.

Dunsdon, J., Harrington, M. \& Cleeve, B. (2008) "The Application of Open System Architecture for Condition Based Maintenance to Complete IVHM", IEEE Aerospace Conference, 1-8 March 2008

Earl, M. (2001) "Knowledge Management Strategies: Toward a Taxonomy", Journal of Management Information Systems, 18 (1) 215-233.

Evans, S., Partidário, P.J., Lambert, J. (2007) "Industrialization as a key element of sustainable productservice solutions", International Journal of Production Research, 45 (18-19) 4225-4246

Fenton, N. (1991) Software Metrics: A Rigorous Approach. London: Chapman \& Hall

Gerring, J. \& McDermott, R. (2007) "An Experimental Template for Case Study Research", American Journal of Political Science, 51 (3) 688-701.

Gijo, E. (2005) "Improving Process Capability of Manufacturing Process by Application of Statistical Techniques", Quality Engineering, 17 (2) 309-315.

Gremler, D. (2004) "The Critical Incident Technique in Service Research", Journal of Service Research, 7 (1) 65-89.

Gruninger, M.; Menzel, C. (2003) "The process specification language (PSL) theory and applications", AI magazine 24(3) 63-74.

Guerra-Zubiaga, D.A., Young, R.I.M. (2008) "Design of a manufacturing knowledge model", International Journal of Computer Integrated Manufacturing, 21(5) 526-539

Hansen, M., Nohria, N. \& Tierney, T. (1999) "What's your strategy for managing knowledge?", Harvard Business Review, March/April 106-116.

Huang, G. \& Mak, K. (1999) "Design for manufacture and assembly on the Internet", Computers in Industry, 38 (1) 17-30.

Lee, J., Ni, J., Djurdjanovic, D., Qiu, H. \& Liao, H. (2006) "Intelligent prognostics tools and emaintenance", Computers in Industry, 57 (6) 476-489.

Maropoulos, P., McKay, K. \& Bramall, D. (2002) "Resource-Aware Aggregate Planning for the Distributed Manufacturing Enterprise", CIRP Annals - Manufacturing Technology, 51 (1) 363-366.

Masri, S., Sheng, L.-H. , Caffrey, J., Nigbor,R.L., Wahbeh, M. \& Abdel-Ghaffar, A. (2004) "Application of a Web-enabled real-time structural health monitoring system for civil infrastructure systems", Smart Materials and Structures, 13 (6) 1269-1283.

Mont, A. \& Tukker, A. (2006) "Product-Service Systems: reviewing achievements and refining the research agenda", Journal of Cleaner Production, 14 (17) 1451-1454.

Morelli, N. (2002) "Designing Product/Service Systems: A Methodological Exploration", Design Issues, 18 (3) 3-17. 
Motorcu, A. \& Güllü, A. (2006) "Statistical process control in machining, a case study for machine tool capability and process capability", Materials \& Design, 27 (5) 364-372.

Noy, N. and McGuinness, D. (2002) "Ontology Development 101: A Guide to Creating Your First Ontology", http://www-ksl.stanford.edu/people/dlm/papers/ontology101/ontology101-noy-mcguinness.html. Accessed 4th December 2008.

Park, H. \& Cutkosky, M.R. (1999) "Framework for modeling dependencies in collaborative engineering processes", Research in engineering design, 11 (2) 84-102.

Scandura Jr, P.A., Garcia-Galan, C., Int, H. \& Glendale, A.Z. (2004) "A unified system to provide crew alerting, electronic checklists and maintenance using IVHM", In: 23rd Digital Avionics Systems Conference, 2004. (DASC 04)

Tukker, A. \& Tischner, U. (2006) "Product-services as a research field: past, present and future. Reflections from a decade of research", Journal of Cleaner Production, 14 (17) 1552-1556.

Wise, R. \& Baumgartner, P. (1999) "Go Downstream: The New Profit Imperative in Manufacturing", Harvard Business Review, 77 (5) 133-141.

Yao, J. \& Warren, S. (2005) "Applying the ISO/IEEE 11073 Standards to Wearable Home Health Monitoring Systems", Journal of Clinical Monitoring and Computing, 19 (6) 427-436.

Ye, Y., Yang, D., Jiang, Z., Tong, L. (2008) " An ontology-based architecture for implementing semantic integration of supply chain management" International Journal of Computer Integrated Manufacturing 21(1) $1-18$.

Yongtao, H. \& Jingying, M. (2006) "A knowledge-based auto-reasoning methodology in hole-machining process planning", Computers in Industry, 57 (4) 297-304.

Yoo, S. \& Kim, Y. (2002) "Web-based knowledge management for sharing product data in virtual enterprises", International Journal of Production Economics, 75 (1-2) 173-183.

Young, R.I.M., Gunendran, A.G., Cutting-Decelle, A.F. \& Gruninger, M. (2007) "Manufacturing knowledge sharing in PLM: a progression towards the use of heavy weight ontologies", International Journal of Production Research, 45 (7) 1505-1519.

$\mathrm{Yu}, \mathrm{K}$., Sheu, S. \& Chen, K. (2005) "The evaluation of process capability for a machining center", The International Journal of Advanced Manufacturing Technology, 33 (5-6) 505-510. 